\title{
Germinated and Ungerminated Seeds Extract from Two Lupinus Species: Biological Compounds Characterization and In Vitro and In Vivo Evaluations
}

\author{
Bogdan Andor, ${ }^{1}$ Corina Danciu, ${ }^{2}$ Ersilia Alexa, ${ }^{3}$ Istvan Zupko, ${ }^{4}$ Elena Hogea, ${ }^{5}$ \\ Andreea Cioca, ${ }^{6}$ Dorina Coricovac, ${ }^{7}$ Iulia Pinzaru, ${ }^{7}$ Jenel Marian Pătraşcu, ${ }^{1}$ Marius Mioc, ${ }^{8}$ \\ Romeo Teodor Cristina, ${ }^{9}$ Codruta Soica, ${ }^{8}$ and Cristina Dehelean ${ }^{7}$ \\ ${ }^{1}$ Department of Orthopedics, University of Medicine and Pharmacy "Victor Babeş", Eftimie Murgu Square, No. 2, \\ 300041 Timişoara, Romania \\ ${ }^{2}$ Department of Pharmacognosy, University of Medicine and Pharmacy "Victor Babeş", Eftimie Murgu Square, \\ No. 2, 300041 Timişoara, Romania \\ ${ }^{3}$ Department of Food Control, Banat's University of Agricultural Sciences and Veterinary Medicine "King Michael I of Romania" from \\ Timisoara, Calea Aradului No. 119, 300641 Timisoara, Romania \\ ${ }^{4}$ Department of Pharmacodynamics and Biopharmacy, University of Szeged, Eötvös u. 6, Szeged 6720, Hungary \\ ${ }^{5}$ Department of Microbiology-Virology, University of Medicine and Pharmacy "Victor Babeş", Eftimie Murgu Square, \\ No. 2, 300041 Timişoara, Romania \\ ${ }^{6}$ Department of Pathology, "Iuliu Hatieganu" University of Medicine and Pharmacy, 400006 Cluj-Napoca, Romania \\ ${ }^{7}$ Department of Toxicology, University of Medicine and Pharmacy "Victor Babeş", Eftimie Murgu Square, \\ No. 2, 300041 Timişoara, Romania \\ ${ }^{8}$ Department of Pharmaceutical Chemistry, University of Medicine and Pharmacy "Victor Babeş", Eftimie Murgu Square, \\ No. 2, 300041 Timişoara, Romania \\ ${ }^{9}$ Department of Pharmacology and Pharmacy, Banat's University of Agricultural Sciences and Veterinary Medicine "King Michael I of \\ Romania" from Timisoara, Calea Aradului No. 119, 300641 Timisoara, Romania
}

Correspondence should be addressed to Iulia Pinzaru; iuliapinzaru@umft.ro

Received 21 July 2016; Revised 2 November 2016; Accepted 17 November 2016

Academic Editor: José L. Ríos

Copyright (C) 2016 Bogdan Andor et al. This is an open access article distributed under the Creative Commons Attribution License, which permits unrestricted use, distribution, and reproduction in any medium, provided the original work is properly cited.

In recent years, nutraceuticals attracted a great amount of attention in the biomedical research due to their significant contribution as natural agents for prevention of various health issues. Ethanolic extracts from the ungerminated and germinated seeds of Lupinus albus L. and Lupinus angustifolius L. were analyzed for the content in isoflavones (genistein) and cinnamic acid derivatives. Additionally, the extracts were evaluated for antimicrobial, antiproliferative, and anti-inflammatory properties, using in vitro and in vivo tests. Germination proved to be a method of choice in increasing the amount of genistein and cinnamic acid derivatives in both Lupinus albus L. and Lupinus angustifolius L. seeds. Biological evaluation of all vegetal extracts revealed a weak therapeutic potential for both ungerminated and germinated seeds.

\section{Introduction}

Both traditional and complementary and alternative medicine of the 21 century have intensively shown the vital role of diet in maintaining human health $[1,2]$. Nutraceuticals have been in the spotlight of research lately due to their significant contribution as natural agents for prevention of various health issues [3, 4]. Lupinus albus L., commonly known as white lupin, and Lupinus angustifolius L., commonly known as the narrow-leafed lupin or blue lupin, members of the Fabaceae family, are two plant species described as nutraceuticals. The Lupinus genus comprises over 200 species. From the chemical point of view, the seeds contain approximately $36-52 \%$ proteins, $30-40 \%$ fibers, and $5-20 \%$ essential oils, 
with values depending on the environmental or genetic conditions $[5,6]$. Other chemical constituents detected in Lupinus sp. were oleic and linoleic acids, isoflavonoids (genistein), carotenoids (zeaxanthin, thiamin, riboflavin, and niacin), and polysaccharides (galactan, cellulose, or hemicellulose). The amount of alkaloid content varies according to the species and the pedoclimatic conditions [6-8]. In terms of protein content, Lupinus species can be considered the strongest potential competitor of Glycine max L., soybean seeds; moreover, Lupinus species can be cultivated in Europe in contrast to soybean [9] which is most frequently found in Asia. Previous studies showed that the extract with high content of alkaloids obtained from L. angustifolius exhibited antimicrobial properties [10]. The group of Smart reported the allergy vaccine obtained from L. angustifolius which successfully suppressed experimental asthma [11]. The hypoglycemic effect of $\gamma$-conglutin-enriched lupin seeds extract was also depicted; $\gamma$-conglutin was described for its insulinmimetic activity in mouse myoblasts $[12,13]$. In a study developed on rats, it was demonstrated that the proteins from $L$. albus seeds were able to reduce cholesterol, consequently displaying cardiopreventive effects $[14,15]$. Antioxidant effects of the seed extract were reported by Wang and Clements [16], while several Lupinus species displayed diuretic, anthelmintic, and emmenagogue activities [17].

The present study aimed (i) to detect the presence of cinnamic acid derivatives and genistein in the germinated and ungerminated seed extracts of two species of Lupinus, $L$. albus and L. angustifolius, and (ii) to screen the in vitro and in vivo effects of these extracts such as antiproliferative, antimicrobial, and anti-inflammatory activity.

\section{Materials and Methods}

2.1. Reagents. The reagents used in the present study were ethanol,methanol, and acetic acid of HPLC analytical grade from Merck (Germany), DMSO (dimethylsulfoxide), TPA (12-O-tetradecanoylphorbol-13-acetate), and acetone from Sigma-Aldrich. The standards for rosmarinic, ferulic, and caffeic acids and genistein were purchased from Sigma-Aldrich and for $p$-coumaric acid from Fluka. The media and the supplements for cell culture were achieved from Lonza Ltd., Basel, Switzerland.

2.2. Cell Lines. All cell lines were purchased from European Collection of Cell Cultures (ECCAC, Salisbury, UK) and were kept in standard conditions.

2.3. Animals. The animals used in the experiment were 8week-old SKH-1 female mice. Mice were purchased from Charles River Laboratories (Budapest, Hungary). The work protocol followed all rules of National Institute of Animal Health (NIAH); animals were maintained during the experiment in standard conditions as follows: $12 \mathrm{~h}$ light-dark cycle, food and water ad libitum, temperature $22-24^{\circ} \mathrm{C}$, and humidity around 55\%.

2.4. Vegetal Extracts. L. albus and L. angustifolius seeds were grown in an experimental field of Banat's University of
Agricultural Sciences and Veterinary Medicine "King Michael I of Romania" from Timisoara $\left(21^{\circ} 13^{\prime} \mathrm{E}\right.$ longitude, $45^{\circ} 45^{\prime} \mathrm{N}$ latitude) and harvested in September 2014. The ungerminated seeds were stored at room temperature in dry environment until analysis. For germination, hot water was poured over the seeds that were kept soaked for 3 days and then sown on moistened germination paper at $20^{\circ} \mathrm{C}$, in the dark, for two weeks. Germinated and ungerminated seeds were then ground and submitted to extraction with ethanol $80 \%$ three times using an FALC LCD series ultrasonic bath for $10 \mathrm{~min}$ at $40 \mathrm{kHz}$ and $28^{\circ} \mathrm{C}$. The ratio between solvent and vegetal product was 1:3; the solvent was finally removed by using a rotary evaporator. The extracts obtained, ungerminated $L$. albus seeds extract (A), ungerminated L. angustifolius seeds extract (B), germinated L. albus seeds extract (C), and germinated L. angustifolius seeds extract (D), were further analyzed.

2.5. Cinnamic Acid (CA) Derivatives and Free Genistein (GY) Determination. The main CA derivatives (ferulic, caffeic, rosmarinic, and coumaric acids) were determined using LCShimadzu chromatograph equipped with degasser DGU20AS, binary pump LC-20AD, SPD-10A UV detector, column thermostat CTO-20AC, and autosampler SIL 20-A. For the separation of compounds PERVAIL column $150 \times 4.6 \mathrm{~mm}$ was used. The chromatographic conditions were as follows: (i) mobile phases A: methanol: acetic acid: water $(90: 2: 8$, v/v) and B: methanol: acetic acid: water $(10: 2: 88, \mathrm{v} / \mathrm{v})$, (ii) gradient program as follows: 0 min B $100 \%$, at $10 \mathrm{~min} \mathrm{~B} 85 \%$, at $15 \mathrm{~min} \mathrm{~B} 50 \%$, at $20 \mathrm{~min} \mathrm{~B} 30 \%$, and at $25 \mathrm{~min} \mathrm{~B} 80 \%$, and (iii) the wavelengths $280 \mathrm{~nm}$ and $320 \mathrm{~nm}$. The calibration curves for CA derivatives were established using dilutions in the range of $5-25 \mu \mathrm{g} / \mathrm{mL}$.

Genistein from extracts obtained was detected using LCShimadzu chromatograph equipped with SPD-10A UV detector and Adsorbosphere UHS C18 column. The chromatographic conditions were operated according to Hanganu et al's method [18]: (i) mobile phases A: acetic acid $0.1 \%(\mathrm{v} / \mathrm{v})$ and B: methanol, (ii) linear gradient: until 2 min B 20\%, at $10 \mathrm{~min} \mathrm{~B} \mathrm{40 \% ,} \mathrm{and} \mathrm{at} 11.50 \mathrm{~min} \mathrm{~B} 45 \%$ and kept until $17 \mathrm{~min}$ at $45 \%$, (iii) column temperature: $48^{\circ} \mathrm{C}$, (iv) the flow rate $0.8 \mathrm{~mL} / \mathrm{min}$, and $(\mathrm{v})$ the wavelengths -248 and $261 \mathrm{~nm}$. The calibration curve of genistein was established using dilutions in the range of $5-100 \mu \mathrm{g} / \mathrm{mL}$.

2.6. In Vitro Antibacterial Activity. A volume of $50 \mathrm{mg} / \mathrm{mL}$ extracts obtained from germinated and ungerminated seeds of the two Lupinus species was screened for their antimicrobial activity against 5 bacterial strains, Staphylococcus aureus (ATCC 25923), Pseudomonas aeruginosa (ATCC 27853), Escherichia coli (ATCC 25922), Klebsiella pneumoniae (ATCC 700603), and Staphylococcus epidermidis (ATCC 14990), by means of the agar disk diffusion method. Chloramphenicol and fluconazole were used as reference.

2.7. Disk Diffusion Method. The antimicrobial activity of the extracts was determined by the disk diffusion method on Muller-Hinton agar using impregnated paper disks. Each bacterial strain was emulsified in sterile saline solution to 
obtain a concentration of $1.5 \times 10^{5} \mathrm{CFU} / \mathrm{mL}$. Muller-Hinton agar plates were inoculated with the respective microbial suspensions. The extracts were dissolved in $1 \mathrm{~mL}$ DMSO. Sterile paper disks $(6 \mathrm{~mm})$ were impregnated with $10 \mu \mathrm{L}$ of emulsified extract solution. These disks were placed on the surface of inoculated plates and incubated at $37^{\circ} \mathrm{C}$ for $24 \mathrm{~h}$. The antimicrobial activity was assessed by measuring the clear inhibition area surrounding the tested extracts.

2.8. MTT Proliferation Assay. The antiproliferative effects of the prepared extracts were determined on a panel of human adherent cancer cell lines of gynecological origin. MCF7 and MDA-MB-231 cells were isolated from breast cancers, while A2780 and $\mathrm{SiHa}$ cells were isolated from ovarian and cervical malignancies, respectively. Cells were cultivated in minimal essential medium supplemented with $10 \%$ fetal bovine serum, $1 \%$ nonessential amino acids, and an antibiotic-antimycotic mixture (Lonza Ltd., Basel, Switzerland). Cancer cells were seeded in a 96-well microplate at the density of 5000/well and allowed to adhere overnight and $200 \mu$ L new medium containing the tested extract was added. After incubation for $72 \mathrm{~h}$ at $37^{\circ} \mathrm{C}$ in humidified air containing $5 \% \mathrm{CO}_{2}$, the percentage of living cells was assessed after addition of $20 \mu \mathrm{L}$ MTT solution. The medium was removed and the precipitated formazan crystals were dissolved in $100 \mu \mathrm{L}$ DMSO during a $60 \mathrm{~min}$ period of shaking at $37^{\circ} \mathrm{C}$. The absorbance values were read at $545 \mathrm{~nm}$, using a microplate reader; wells with untreated cells were utilized as control and inhibition \% values were calculated. All in vitro experiments were carried out on two microplates with at least five parallel wells. Cisplatin was used as positive control. Stock solutions of the tested substances $(50 \mathrm{mM})$ were prepared in DMSO.

2.9. Experimental Design of the Study. The animal model of ear inflammation was performed on $\mathrm{SKH}-1$ hairless mice. The protocol applied was as the one described in the literature [19] with several modifications: the ear edema was induced by topical application of TPA $2 \mu \mathrm{g} /$ ear dissolved in $20 \mu \mathrm{L}$ acetone. The volume of TPA solution was applied on both the inner and the outer surfaces of the mouse ear. The mice were divided in the following groups: control group, Group A (mice topically treated with acetone), Group B, mice topically treated with TPA solution, Group C, mice topically treated with TPA solution followed after 30 minutes by the application of $100 \mu \mathrm{L}$ ungerminated $L$. albus seeds extract $(50 \mathrm{mg} / \mathrm{mL})$, Group D, mice topically treated with TPA solution followed after 30 minutes by the application of $100 \mu \mathrm{L}$ germinated L. albus seeds extract $(50 \mathrm{mg} / \mathrm{mL})$, Group $\mathrm{E}$, mice topically treated with TPA solution followed after 30 minutes by the application of $100 \mu \mathrm{L}$ of ungerminated $L$. angustifolius seeds extract $(50 \mathrm{mg} / \mathrm{mL})$, and Group F, mice topically treated with TPA solution followed after 30 minutes by the application of $100 \mu \mathrm{L}$ of germinated L. angustifolius seeds extract $(50 \mathrm{mg} / \mathrm{mL})$. At $4 \mathrm{~h}$ after application of the test extracts, the mice were sacrificed under anesthesia by cervical dislocation and $6 \mathrm{~mm}^{2}$ diameter ear punch biopsies were collected and histopathologically analyzed.

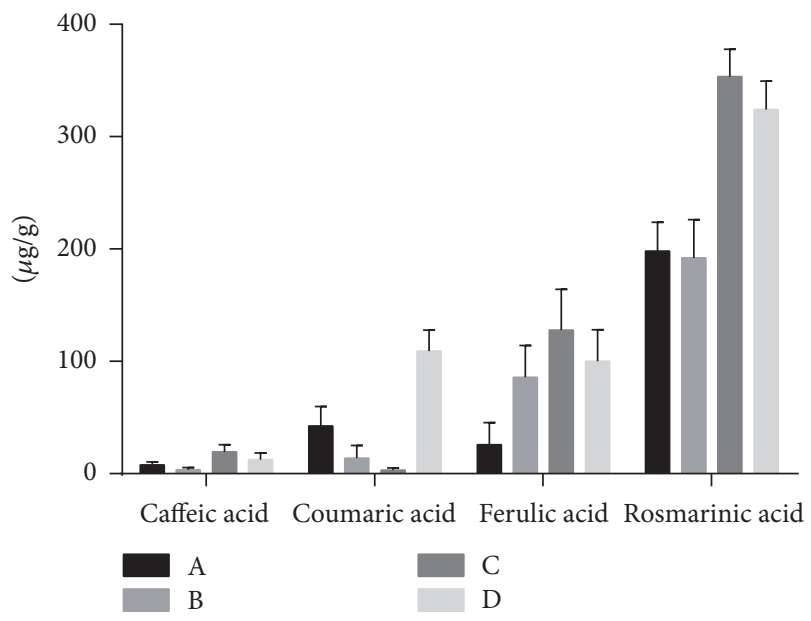

Figure 1: Cinnamic acid (CA) derivatives determination of the selected extracts expressed as $\mu \mathrm{g} / \mathrm{g}$ (two-way ANOVA, Interaction, $p=0.0022$, Row Factor, $p<0.0001$, and Column Factor, $p=$ $0.0002)$.

2.10. Histopathological Analysis. Samples of mouse ear were fixed in $10 \% \mathrm{v} / \mathrm{v}$ buffered formalin solution and then embedded in paraffin. Six-micrometer-thick serial slides were sectioned and stained with the conventional hematoxylin-eosin dye $(\mathrm{H} \& \mathrm{E})$. Image acquisition and analysis were performed using a Nikon Eclipse E600 microscope. Inflammation was quantified as 1, mild; 2 , moderate; and 3 , severe.

2.11. Statistics. The Prism software package (GraphPad Prism 4.03 for Windows) was used for data presentation. The experiment was repeated three times and results were presented as mean $\pm \mathrm{SD}$. Paired Student's $t$-tests and one-way or twoway ANOVA were applied to evaluate statistical significance $\left({ }^{*} p<0.05 ;{ }^{* *} p<0.01\right.$; and $\left.{ }^{* * *} p<0.001\right)$.

\section{Results and Discussions}

One of the objectives of the present study consisted in detecting the presence of cinnamic acid derivatives and genistein in germinated and ungerminated seed extracts of $L$. albus and $L$. angustifolius. According to our results, it was shown that the caffeic acid content was increased in germinated extracts as compared to ungerminated ones as follows: 1.304 \pm $0.421 \mu \mathrm{g} / \mathrm{g}$ (A, ungerminated $L$. albus seeds extract) versus $3.389 \pm 1.053 \mu \mathrm{g} / \mathrm{g}(\mathrm{C}$, germinated $L$. albus seeds extract) and $0.531 \pm 0.331 \mu \mathrm{g} / \mathrm{g}$ (B, ungerminated $L$. angustifolius seeds extract) versus $2.114 \pm 1.003 \mu \mathrm{g} / \mathrm{g}$ ( $\mathrm{D}$, germinated $L$. angustifolius seeds extract). Regarding the content of the other three cinnamic acid derivatives (coumaric, ferulic, and rosmarinic acids), an increase in the germinated extracts of L. angustifolius was determined, with the highest value being obtained for rosmarinic acid (coumaric acid $<$ ferulic acid $<$ rosmarinic acid; Figure 1). The germinated extracts of L. albus induced an increase of ferulic and rosmarinic acids content, whereas the coumaric acid content was reduced (Figure 1). In the present study, caffeic and coumaric acids were found in low concentrations in both germinated and ungerminated 
TABLE 1: Validation parameters for cinnamic acid (CA) derivatives and free genistein (GY).

\begin{tabular}{lccccc}
\hline Compounds & Retention time $\left(r_{T}\right)$ & Regression equations & Regression coefficient $\left(R^{2}\right)$ & LOD $(\mu \mathrm{g} / \mathrm{mL})$ & $\mathrm{LOQ}(\mu \mathrm{g} / \mathrm{mL})$ \\
\hline Caffeic acid & 10.4 & $y=2.36 x-2.34$ & $0.998^{\dagger}$ & ${ }^{\dagger} 0.5$ & 0.7 \\
Coumaric acid & 15.4 & $y=2.00 x-2.65$ & 0.996 & 0.5 & 0.7 \\
Ferulic acid & 16.1 & $y=2.96 x-5.28$ & 0.989 & 0.5 & 0.4 \\
Rosmarinic acid & 17.2 & $y=4.22 x-2.02$ & 0.990 & 0.7 & 0.4 \\
Genistein & 14.0 & $y=1.77 x-3.95$ & 0.986 & 0.6 \\
\hline
\end{tabular}

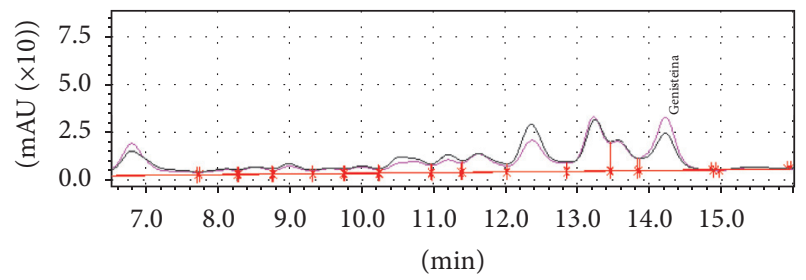

- Detector A Ch1: $248 \mathrm{~nm}$

— Detector A Ch2: $261 \mathrm{~nm}$

(a)

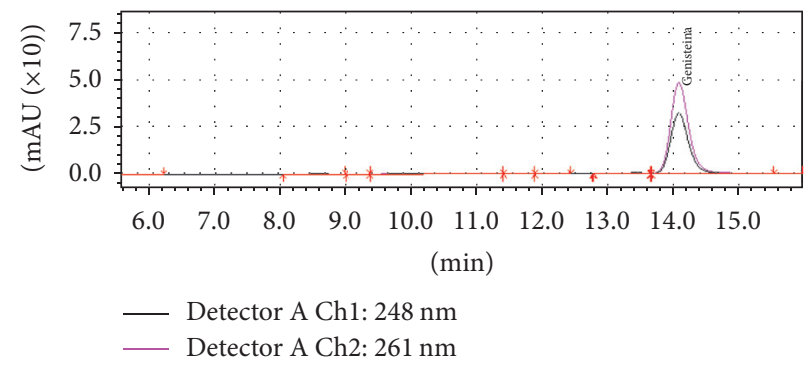

(c)

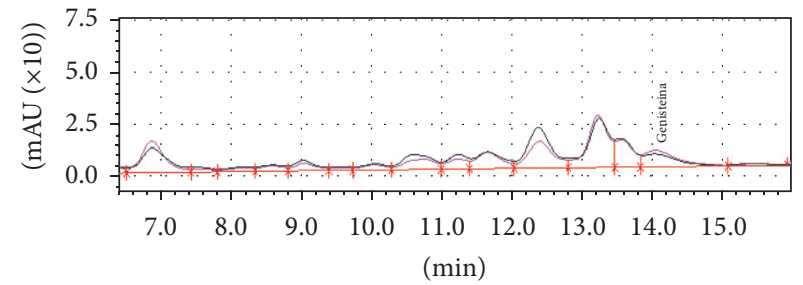

_ Detector A Ch1: $248 \mathrm{~nm}$

_ Detector A Ch2: $261 \mathrm{~nm}$

(b)

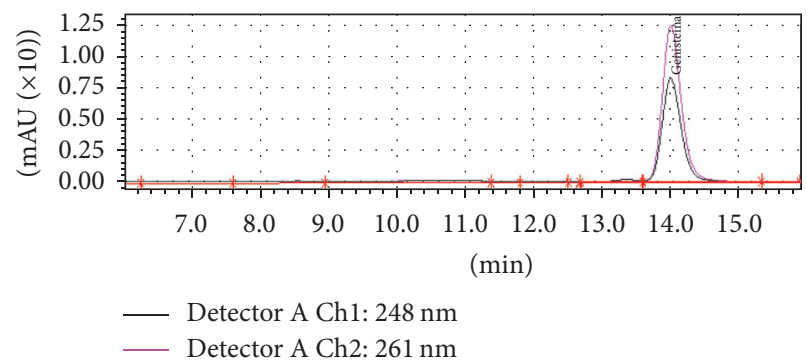

(d)

FIGURE 2: HPLC chromatogram for GY determination: (a) extract from ungerminated seed of Lupinus albus; (b) Lupinus angustifolius; (c) germinated seed of Lupinus albus; (d) Lupinus angustifolius. GY: genistein. Data collected at $261 \mathrm{~nm}$ (pink line) and $248 \mathrm{~nm}$ (black line).

seeds as compared to the ferulic and rosmarinic acids. Similar results were reported by Siger et al. in a study using ungerminated seeds; according to these authors, the content of caffeic acid was $0.58 \mu \mathrm{g} / \mathrm{g}$ in $L$. albus seeds and $0.84 \mu \mathrm{g} / \mathrm{g}$ in L. angustifolius seeds [20]. The presence of cinnamic acid derivatives in germinated and ungerminated seeds of Lupinus sp. was also reported by other research groups [21, 22]. Luthria and Pastor-Coralles described in 2005 the presence of ferulic and coumaric acids in several varieties of Phaseolus vulgaris Linnaeus beans in the range of $106-229 \mu \mathrm{g} / \mathrm{g}$ for ferulic acid and $17-124 \mu \mathrm{g} / \mathrm{g}$ for coumaric acid [23]. Siger et al. showed that germination changes the quantitative and qualitative polyphenolic composition of lupin seeds, significantly increasing the flavonoids amount [20].

HPLC analysis was performed in order to detect the expression of genistein, the most important isoflavone present in both germinated and ungerminated seeds of the two Lupinus sp. The HPLC chromatograms of germinated and ungerminated lupin seeds are presented in Figure 2. The validation parameters (the regression equations, retention times, limits of detection, and limits of quantification) for CA derivatives and GY were presented in Table 1. The limit of detection (LOD) represents the amount of compounds that could be detected with a signal-to-noise ratio ( $\mathrm{S} / \mathrm{N} \geq$ 3 ), while the limit of quantification (LOQ) represents the lowest concentration for which $\mathrm{S} / \mathrm{N} \geq 5$. Intraday and interday accuracy and precision values of the method were detected. In determining the intraday accuracy and precision, six samples were injected within the same day. This procedure was repeated once a day for 3 consecutive days to evaluate the interday precision. The intraday coefficient of variation (RSD \%) ranged from 2.50 to $14.5 \%$ and the accuracy from 94.4 to $98.0 \%$, while the interday RDS (\%) varied between 6.54 and $16.1 \%$ and the accuracy from 93.5 to $97.4 \%$. The results indicated that the assay was reproducible and accurate.

The results presented in Figure 3 showed that L. albus seeds extract (A) had a slightly higher genistein concentration as compared to L. angustifolius seeds extract (B), namely, $9.395 \pm 0.813 \mu \mathrm{g} / \mathrm{g}$ versus $7.335 \pm 2.043 \mu \mathrm{g} / \mathrm{g}$, values that indicate a relatively low amount of genistein. The two weeks of germination significantly increased genistein concentration as follows: $20.74 \pm 2.899 \mu \mathrm{g} / \mathrm{g}$ genistein in germinated $L$. albus seeds extract $(\mathrm{C})$ and $18.83 \pm 3.549 \mu \mathrm{g} / \mathrm{g}$ genistein in germinated L. angustifolius seeds extract (D). Genistein content in several cultivars of L. albus stems varies in a large range: $0.2-27.44 \mathrm{ppm}$ [24], 48-84 ppm [25], and $116.1 \mathrm{ppm}$ in 
TABLE 2: Antimicrobial activity of the selected extracts expressed as zone of inhibition (mm).

\begin{tabular}{|c|c|c|c|c|c|c|}
\hline Reference strain & Chloramphenicol $30 \mu \mathrm{g}$ & Fluconazole $25 \mu \mathrm{g}$ & $\mathrm{A}$ & B & $\mathrm{C}$ & $\mathrm{D}$ \\
\hline \multicolumn{7}{|c|}{ Zone of inhibition $(\mathrm{mm})$} \\
\hline S. aureus ATCC 25923 & 30 & 0 & 0 & 0 & 0 & 0 \\
\hline P. aeruginosa ATCC 7853 & 0 & 0 & 0 & 0 & 0 & 0 \\
\hline E. coli ATCC 25922 & 30 & 15 & 0 & 0 & 0 & 0 \\
\hline K. pneumoniae ATCC 700603 & 16 & 0 & 0 & 0 & 0 & 15 \\
\hline S. epidermidis ATCC 14990 & 30 & 0 & 0 & 0 & 0 & 0 \\
\hline
\end{tabular}

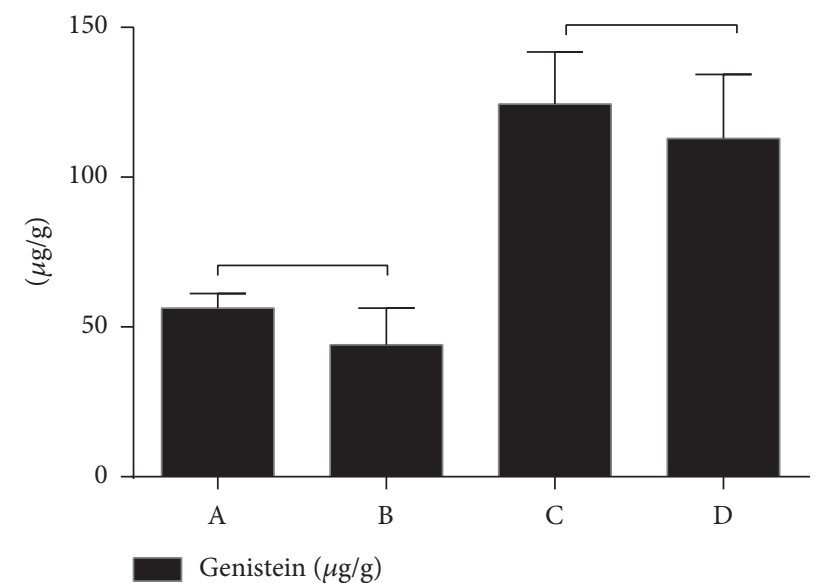

FIGURE 3: Genistein amount $(\mu \mathrm{g} / \mathrm{g})$ in the analyzed samples (paired Student's $t$-test, $p<0.029$, respectively, $p<0.036$ ).

seedlings [26], while the reported values in seeds are lower (1.5 ppm) [27]. Germination induces the increase by five times of the amount of isoflavones in soybeans after 1 week of germination, mechanism that can be explained through the activation of b-glucosidase enzymes in the soaking step prior to germination or by the germination metabolism [28].

The selected extracts were assessed for their antimicrobial potential against five bacterial strains: S. aureus (ATCC 25923), P. aeruginosa (ATCC 27853), E. coli (ATCC 25922), K. pneumoniae (ATCC 700603), and S. epidermidis (ATCC 14990). Chloramphenicol $30 \mu \mathrm{g}$ and fluconazole $25 \mu \mathrm{g}$ were used as references. Samples showed no antimicrobial activity on the tested strains except for sample D which created a $15 \mathrm{~mm}$ zone of inhibition on K. pneumonia strain. The results were presented in Table 2. The extracts of both germinated and ungerminated seeds of the two Lupinus sp. show poor antimicrobial activity on the selected bacterial strains. Previous papers reported the antibacterial and antifungal activity of the alkaloid extract of L. angustifolius seeds. The extract exhibited significant activity on $B$. subtilis, $S$. aureus, and $P$. aeruginosa at MICs of $62.5 \mu \mathrm{g} / \mathrm{mL}$ [10]. Lampart-Szczapa et al. showed that extracts obtained from three species of Lupin sp. (albus, luteus, and angustifolius) seeds cotyledons did not exhibit any antibacterial activity against E. coli and B. subtilis, whereas extracts obtained from testas induced inhibition zones between 14 and $27 \mathrm{~mm}$. They also reported the direct correlation between the antibacterial activity and the amount of free phenolic acids [9]. Current data correlated with poor literature reports in terms of the antimicrobial activity of various Lupinus sp. seeds allowed us to conclude that extracts from the seeds of these species are not the first choice as antimicrobial agents. On the other hand, extracts from $L$. arboreus leaves exhibited a broad spectrum of activity against certain bacterial strains [29]. Also, the root extract of Sudanese L. termis showed moderate antimicrobial activity [30].

The four extracts obtained in the present study were analyzed for their antiproliferative capacity against four cancer cell lines: MCF7, MDA-MB-231 (breast cancers), A2780 (ovarian cancer), and $\mathrm{SiHa}$ (cervical cancer). Our results showed a poor antiproliferative activity as depicted in Table 3. None of the selected extracts was active against the A2780 ovarian cancer cell line. For the breast cancer cell lines MCF7 and MDA-MB-231, the results showed an antiproliferative activity only at the highest concentration used in the case of ungerminated L. angustifolius seeds extract (B). A similar effect was found at the same concentration for the germinated L. angustifolius seeds extract (D). According to our data, germination does not seem to induce a significant effect on the antiproliferative capacity against the tumor cell lines tested in the study. SiHa cervical cancer cell line seems to be more sensitive to the tested extracts; the antiproliferative activities elicited by the highest concentration of extracts (C) and (D) were around 30\%. Previous studies in this field reported that a volume of $200 \mu \mathrm{g} / \mathrm{mL}$ ethanolic extracts from the root and shoot of L. angustifolius displayed antiproliferative activity against MCF-7 and BT20 breast cancers cell lines [31]; additionally, genistein-8-C-glucoside from $L$. luteus induced DNA damage and reduced cell viability of the mouse embryonic fibroblast, NIH 3T3 cell line, when used in concentrations $>20 \mu \mathrm{M}$ [32].

Histological analysis of the ears revealed the presence of an infiltrate of mixed inflammatory cells, with the polymorphonuclear leukocytes being more abundant and only few lymphocytes. One can notice that ear samples collected from groups A, C, F, and G showed moderate inflammation, while groups $\mathrm{B}, \mathrm{D}$, and $\mathrm{E}$ disclosed severe inflammatory response, with abundant cell influx (Figure 4).

The values recorded for ear edema in the tested groups are shown in Figure 5. No anti-inflammatory potential was noticed for the ungerminated seeds extracts of the two Lupinus sp. Germinated seeds of both species presented mild anti-inflammatory activity. These results confirmed the $\mathrm{H} \& \mathrm{E}$ findings. Studies on animal models showed the mild antiinflammatory activity provided by the extracts from germinated seeds of the two Lupinus sp; recent in vitro studies 
TABLE 3: Antiproliferative activity of the selected extracts expressed as inhibition \% against the mentioned cell lines. Extracts eliciting less than $10 \%$ inhibition are considered ineffective and the exact values were not presented for clarity purposes.

\begin{tabular}{|c|c|c|c|c|c|}
\hline \multirow{2}{*}{ Extract } & \multirow{2}{*}{ Final concentration } & \multicolumn{4}{|c|}{ Inhibition (\%) \pm SEM } \\
\hline & & A2780 & MCF7 & MDA-MB-231 & $\mathrm{SiHa}$ \\
\hline \multirow{3}{*}{ A } & $15 \mu \mathrm{g} / \mathrm{mL}$ & - & - & - & - \\
\hline & $50 \mu \mathrm{g} / \mathrm{mL}$ & - & - & - & - \\
\hline & $150 \mu \mathrm{g} / \mathrm{mL}$ & - & - & - & $11.42 \pm 1.55$ \\
\hline \multirow{3}{*}{ B } & $15 \mu \mathrm{g} / \mathrm{mL}$ & - & - & - & - \\
\hline & $50 \mu \mathrm{g} / \mathrm{mL}$ & - & - & - & - \\
\hline & $150 \mu \mathrm{g} / \mathrm{mL}$ & - & $10.54 \pm 2.46$ & $11.40 \pm 1.99$ & $18.23 \pm 3.23$ \\
\hline \multirow{3}{*}{$\mathrm{C}$} & $15 \mu \mathrm{g} / \mathrm{mL}$ & - & - & - & - \\
\hline & $50 \mu \mathrm{g} / \mathrm{mL}$ & - & - & - & $11.65 \pm 3.07$ \\
\hline & $150 \mu \mathrm{g} / \mathrm{mL}$ & - & - & - & $27.09 \pm 0.85$ \\
\hline \multirow{3}{*}{ D } & $15 \mu \mathrm{g} / \mathrm{mL}$ & - & - & - & - \\
\hline & $50 \mu \mathrm{g} / \mathrm{mL}$ & - & - & - & $11.26 \pm 2.26$ \\
\hline & $150 \mu \mathrm{g} / \mathrm{mL}$ & - & $16.83 \pm 3.55$ & $10.83 \pm 1.10$ & $32.53 \pm 1.49$ \\
\hline
\end{tabular}

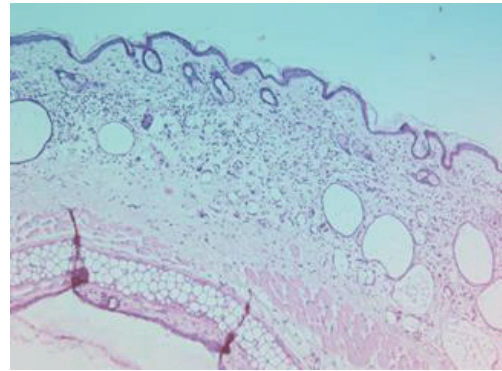

(a)

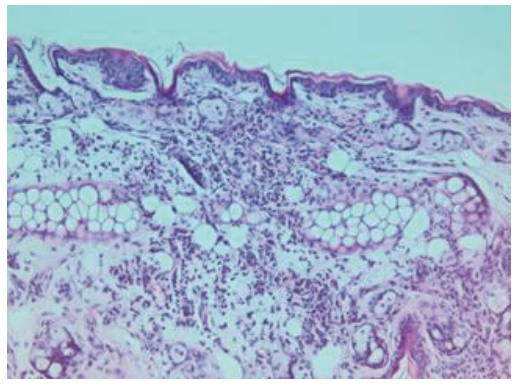

(d)

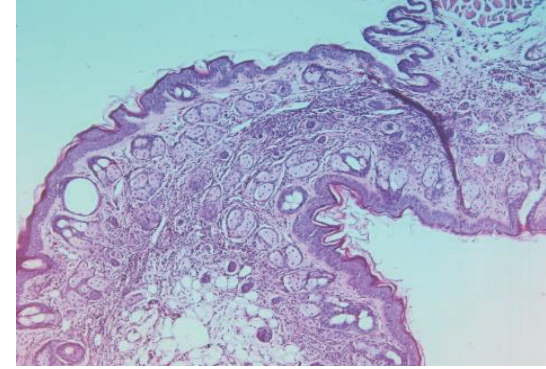

(b)

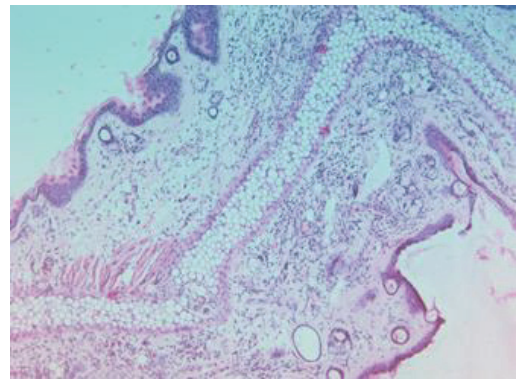

(e)

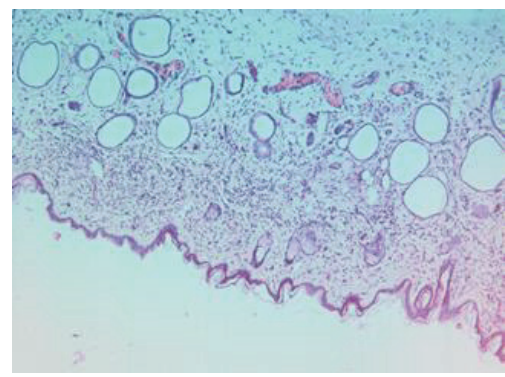

(g)

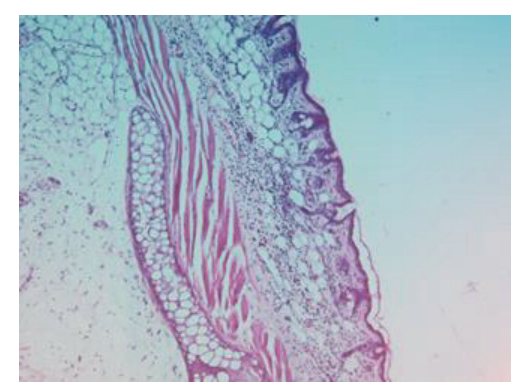

(c)

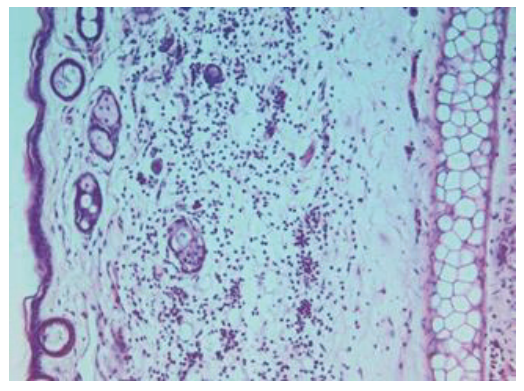

(f)

FIGURE 4: Ear sections corresponding to groups (a)-(g) were stained with H\&E and analyzed for inflammatory response. Magnification 20x; scale bar: $150 \mu \mathrm{m}$. 


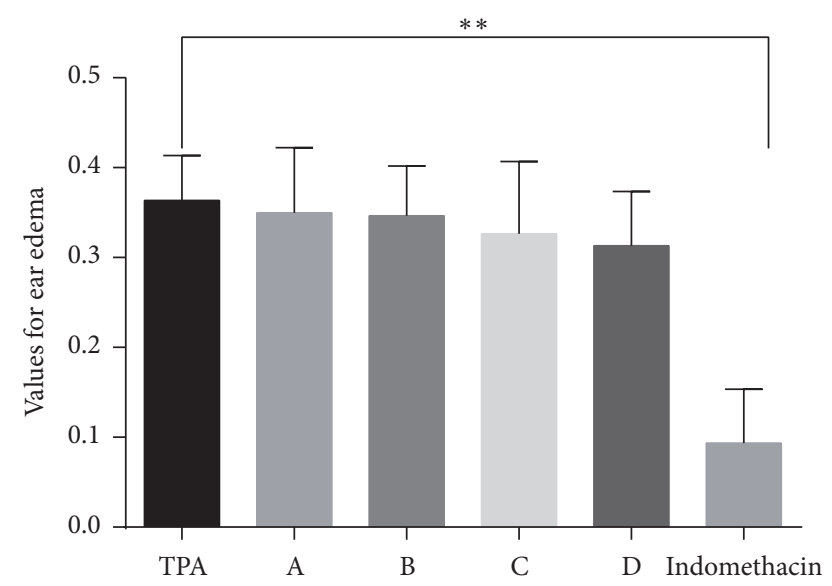

Figure 5: Ear edema values for extracts A, B, C, and D using TPA as blank and indomethacin $1 \%$ as reference for the anti-inflammatory activity (one-way ANOVA, $p=0.0019, * *$ ).

have also reported the anti-inflammatory activity of protein hydrolysates from $L$. angustifolius in THP-1-derived macrophages [33]. In another study focusing on the assessment of topical applications of curcuminoids and flavonoids on male albino rats, the group of Hamzah showed that the decrease of edema percentage induced by ethanol fraction lupines was $18 \%$, while chloroform fraction lupines led to $11.3 \%$ edema inhibition [34]. Additionally, aqueous $L$. mutabilis sweet extract was described to produce gastric anti-inflammatory and antisecretory activities in rats [35]. These results confirmed and completed the data existing in the literature regarding the biological characterization of the compounds and in vitro and in vivo evaluation of germinated and ungerminated seeds extract from the two Lupinus species L. albus and L. angustifolius.

\section{Conclusion}

The study showed that germination is an excellent natural method that can be employed for the augmentation of some active plant secondary metabolites content as isoflavones and cinnamic acid derivatives in nutraceuticals like $L$. albus and $L$. angustifolius seeds. Biological evaluation of the antimicrobial, antiproliferative, and anti-inflammatory activity of all vegetal extracts revealed a weak therapeutic potential for both ungerminated and germinated seeds. As described in the present study, germinated seed of different Lupinus sp. can represent a valuable source for the intake of genistein and cinnamic acid derivatives and directly correlated their beneficial effects on the human body.

\section{Competing Interests}

The authors wish to confirm that there are no known competing interests associated with this publication and there has been no significant financial support for this work that could have influenced its outcome.

\section{Authors' Contributions}

Bogdan Andor and Corina Danciu have equal contribution.

\section{References}

[1] S. Friel and L. Ford, "Systems, food security and human health," Food Security, vol. 7, no. 2, pp. 437-451, 2015.

[2] G. Pang, J. Xie, Q. Chen, and Z. Hu, "How functional foods play critical roles in human health," Food Science and Human Wellness, vol. 1, no. 1, pp. 26-60, 2012.

[3] A. Rahal, Mahima, A. K. Verma et al., "Phytonutrients and nutraceuticals in vegetables and their multi-dimensional medicinal and health benefits for humans and their companion animals: a review," Journal of Biological Sciences, vol. 14, no. 1, pp. 1-19, 2014.

[4] L. Das, E. Bhaumik, U. Raychaudhuri, and R. Chakraborty, "Role of nutraceuticals in human health," Journal of Food Science and Technology, vol. 49, no. 2, pp. 173-183, 2012.

[5] K. P. Akritidu, V. V. Boinik, and O. V. Demeshko, "Organic acids from lupinus polyphyllus roots," Chemistry of Natural Compounds, vol. 49, no. 3, pp. 501-502, 2013.

[6] A. A. Mohamed and P. Rayas-Duarte, "Composition of Lupinus albus," Cereal Chemistry, vol. 72, no. 6, pp. 643-647, 1995.

[7] M. Erbaş, M. Certel, and M. K. Uslu, "Some chemical properties of white lupin seeds (Lupinus albus L.)," Food Chemistry, vol. 89, no. 3, pp. 341-345, 2005.

[8] D. Ballester, E. Yáñez, R. García et al., "Chemical composition, nutritive value, and toxicological evaluation of two species of sweet lupine (Lupinus albus and Lupinus luteus)," Journal of Agricultural and Food Chemistry, vol. 28, no. 2, pp. 402-405, 1980.

[9] E. Lampart-Szczapa, A. Siger, K. Trojanowska, M. NogalaKalucka, M. Malecka, and B. Pacholek, "Chemical composition and antibacterial activities of lupin seeds extracts," Molecular Nutrition \& Food Research, vol. 47, no. 5, pp. 286-290, 2003.

[10] N. Erdemoglu, S. Ozkan, and F. Tosun, "Alkaloid profile and antimicrobial activity of Lupinus angustifolius L. alkaloid extract," Phytochemistry Reviews, vol. 6, no. 1, pp. 197-201, 2007.

[11] V. Smart, P. S. Foster, M. E. Rothenberg, T. J. V. Higgins, and S. P. Hogan, "A plant-based allergy vaccine suppresses experimental asthma via an IFN- $\gamma$ and $\mathrm{CD} 4^{+} \mathrm{CD} 45 \mathrm{RB}^{\text {low }} \mathrm{T}$ cell-dependent mechanism," The Journal of Immunology, vol. 171, no. 4, pp. 2116-2126, 2003.

[12] J. C. Bertoglio, M. A. Calvo, J. L. Hancke et al., "Hypoglycemic effect of lupin seed $\gamma$-conglutin in experimental animals and healthy human subjects," Fitoterapia, vol. 82, no. 7, pp. 933-938, 2011.

[13] I. Terruzzi, P. Senesi, C. Magni et al., "Insulin-mimetic action of conglutin- $\gamma$, a lupin seed protein, in mouse myoblasts," Nutrition, Metabolism and Cardiovascular Diseases, vol. 21, no. 3, pp. 197-205, 2011.

[14] C. R. Sirtori, M. R. Lovati, C. Manzoni et al., "Proteins of white lupin seed, a naturally isoflavone-poor legume, reduce cholesterolemia in rats and increase LDL receptor activity in HepG2 cells," Journal of Nutrition, vol. 134, no. 1, pp. 18-23, 2004.

[15] G. G. Fontanari, J. P. Batistuti, R. J. D. Cruz, P. H. N. da Saldiva, and J. A. G. Arêas, "Cholesterol-lowering effect of whole lupin (Lupinus albus) seed and its protein isolate," Food Chemistry, vol. 132, no. 3, pp. 1521-1526, 2012. 
[16] S. Wang and J. Clements, "Antioxidant activities of lupin seeds," in Lupins for Health and Wealth: Proceedings of the 12th International Lupin Conference, Fremantle, Western Australia 14-18 September 2008, pp. 546-551, International Lupin Association, 2008.

[17] A. El-Moursi, K. M. Gamal El-Din, and S. A. Tarraf, "Physiological response of lupine plant (Lupinus termis L.) to heat hardening," American-Eurasian Journal of Agricultural \& Environmental Sciences, vol. 12, no. 5, pp. 660-663, 2012.

[18] D. Hanganu, L. Vlase, and N. Olah, "Phytochemical analysis of isoflavons from some Fabaceae species extracts," Notulae Botanicae Horti Agrobotanici Cluj-Napoca, vol. 38, no. 1, pp. 5760, 2010.

[19] T. Kumar and V. Jain, "Antinociceptive and anti-inflammatory activities of bridelia retusa methanolic fruit extract in experimental animals," The Scientific World Journal, vol. 2014, Article ID 890151, 12 pages, 2014.

[20] A. Siger, J. Czubinski, P. Kachlicki, K. Dwiecki, E. LampartSzczapa, and M. Nogala-Kalucka, "Antioxidant activity and phenolic content in three lupin species," Journal of Food Composition and Analysis, vol. 25, no. 2, pp. 190-197, 2012.

[21] M. Dueñas, T. Hernández, I. Estrella, and D. Fernández, "Germination as a process to increase the polyphenol content and antioxidant activity of lupin seeds (Lupinus angustifolius L.)," Food Chemistry, vol. 117, no. 4, pp. 599-607, 2009.

[22] A. R. Ahmed, "Influence of chemical properties of wheat-lupine flour blends on cake quality," American Journal of Food Science and Technology, vol. 2, no. 2, pp. 67-75, 2014.

[23] D. L. Luthria and M. A. Pastor-Corrales, "Phenolic acids content of fifteen dry edible bean (Phaseolus vulgaris L.) varieties," Journal of Food Composition and Analysis, vol. 19, no. 2-3, pp. 205-211, 2006.

[24] A. D’Agostina, G. Boschin, D. Resta, P. Annicchiarico, A. Arnoldi, and J. B. Berger, "Evolution of isoflavones during the growth of plants of Lupinus albus," in Proceedings of the 12th International Lupin Conference on Lupins for Health and Wealth, J. A. Palta and J. B. Berger, Eds., pp. 14-18, Fremantle, Western Australia, 2008.

[25] P. B. Kaufman, J. A. Duke, H. Brielmann, J. Boik, and J. E. Hoyt, "A comparative survey of leguminous plants as sources of the isoflavones, genistein and daidzein: implications for human nutrition and health," Journal of Alternative and Complementary Medicine, vol. 3, no. 1, pp. 7-12, 1997.

[26] Y. Shibuy, Y. Sugimura, S. Tahara, and J. Mizutani, “Accumulation of isoflavones in lupin seedings treated with copper chloride," Bioscience, Biotechnology, and Biochemistry, vol. 56, no. 4, pp. 690-691, 1992.

[27] S. Bhagwat, D. B. Haytowitz, and J. M. Holden, "USDA Database for the Isoflavone Content of Selected Food," 2008, http://www .ars.usda.gov/SP2UserFiles/Place/80400525/Data/isoflav/Isoflav_R2.pdf.

[28] M. D. Chiarello, J.-L. Le Guerroué, C. M. S. Chagas, O. L. Franco, E. Bianchini, and M. J. João, "Influence of heat treatment and grain germination on the isoflavone profile of soy milk," Journal of Food Biochemistry, vol. 30, no. 2, pp. 234-247, 2006.

[29] S. C. Ohadoma, I. Nnatuanya, L. U. Amazu, and C. E. Okolo, "Antimicrobial activity of the leaf extract and fractions of Lupinus arboreus," Journal of Medicinal Plants Research, vol. 8, no. 8, pp. 386-391, 2014.

[30] A. O. A. Hamed and S. M. H. Ayoub, "Chemical composition and antimicrobial activity of Sudanese Lupinus termis L. root extracts," The Pharma Innovation Journal, vol. 4, no. 5, pp. 1-4, 2015.

[31] J. Stapel, C. Oppermann, D. U. Richter, W. Ruth, and V. Briese, "Anti-carcinogenic effects of ethanolic extracts from root and shoot of Lupinus angustifolius on breast carcinoma cell lines MCF-7 and BT20," Journal of Medicinal Plants Research, vol. 9, no. 17, pp. 561-568, 2015.

[32] A. Rucinska and T. Gabryelak, "Effect of genistein-8-C-glucoside from Lupinus luteus on DNA damage assessed using the comet assay in vitro," Cell Biology International, vol. 33, no. 2, pp. 247-252, 2009.

[33] M. D. C. Millán-Linares, B. Bermúdez, M. M. Yust, F. Millán, and J. Pedroche, "Anti-inflammatory activity of lupine (Lupinus angustifolius L.) protein hydrolysates in THP-1-derived macrophages," Journal of Functional Foods, vol. 8, no. 1, pp. 224233, 2014.

[34] M. M. Hamzah, "Evaluation of topical preparations containing Curcuma, Acacia and Lupinus extracts as an anti-inflammatory drugs," International Journal of Applied Research in Natural Products, vol. 4, no. 2, pp. 19-23, 2011.

[35] C. F. Gamarra, B. Castañeda, B. M. Castillo, and H. J. Martinez, "Gastric anti-inflamatory and anti-secretory activities in rats treated with an aqueous Lupinus mutabilis extract," in México, Where Old and New World Lupins Meet. Proceedings of the 11th International Lupin Conference, Guadalajara, Jalisco, Mexico, 4-9 May 2005, pp. 347-349, International Lupin Association, 2006. 


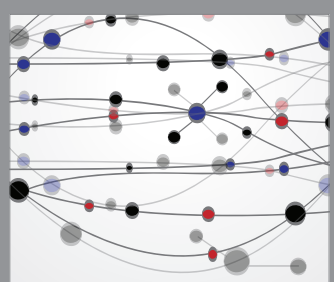

The Scientific World Journal
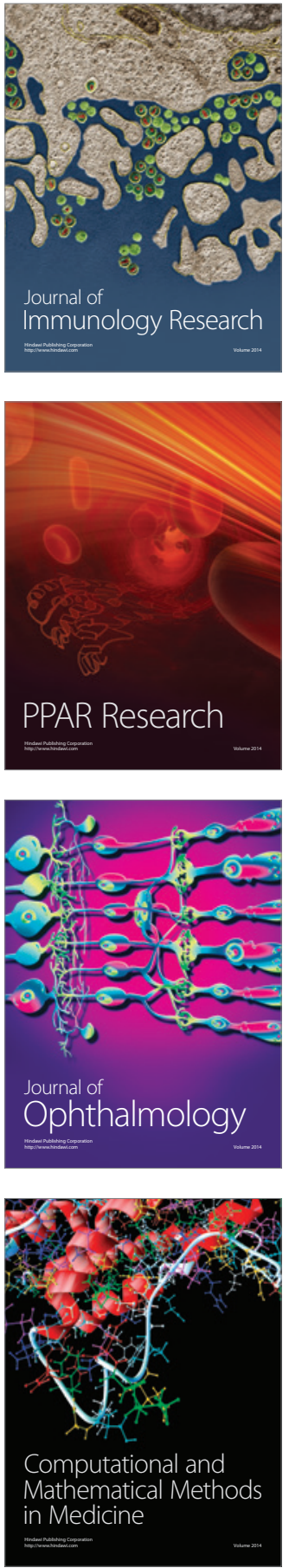

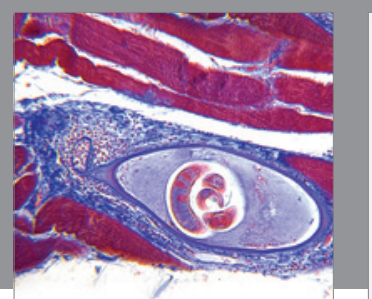

Gastroenterology Research and Practice

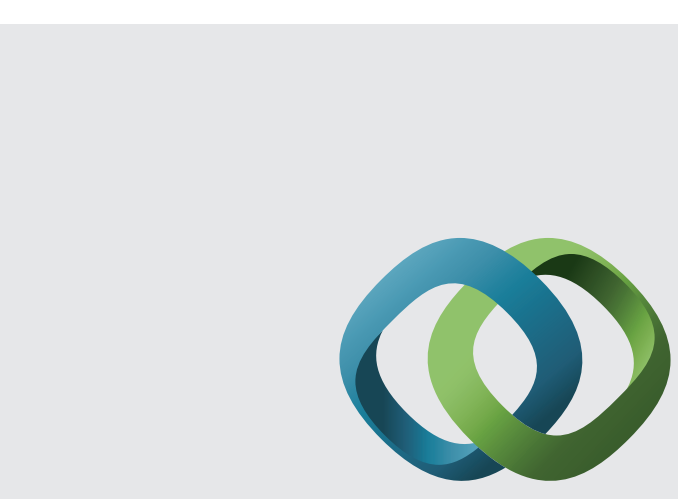

\section{Hindawi}

Submit your manuscripts at

http://www.hindawi.com
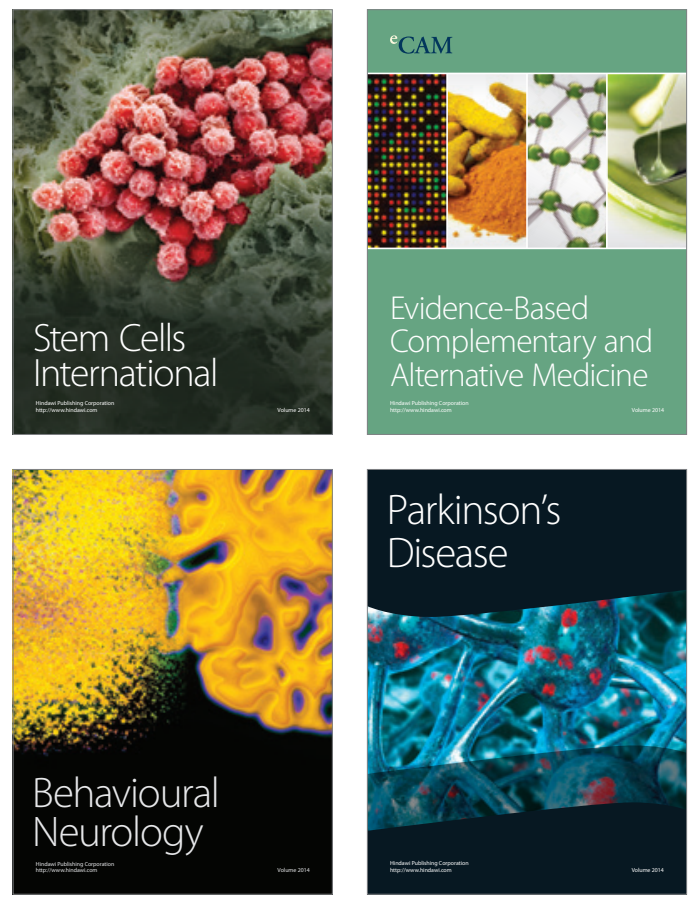
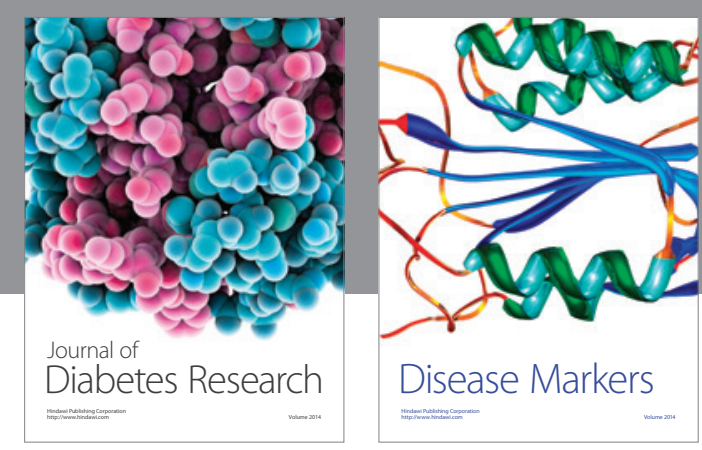

Disease Markers
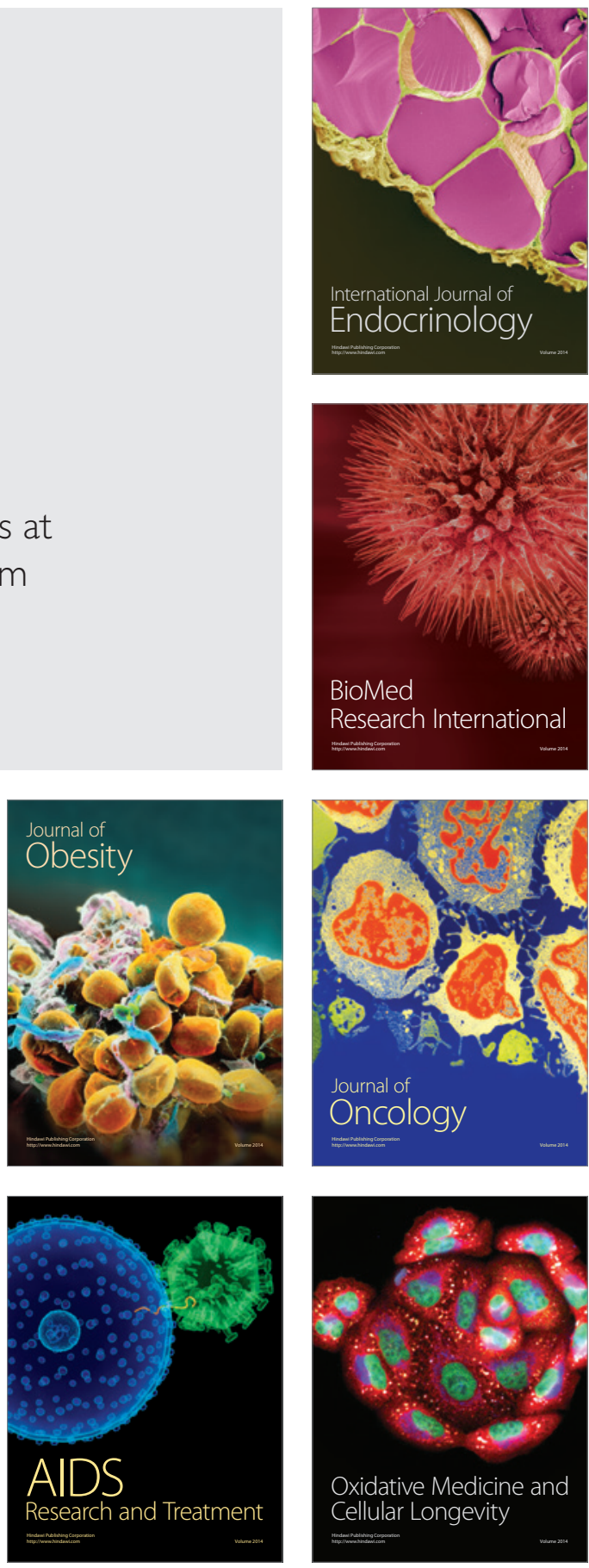